DESPESAS PÚBLICAS COM SAÚDE E EDUCAÇÃO NOS MUNICÍPIOS DO ESPÍRITO SANTO: Uma investigação empírica

\author{
Edson Zambon Monte \\ Universidade Federal do Espírito Santo (UFES) \\ Thayane Pinheiro Largura \\ Sistema de Cooperativas de Crédito do Brasil - Central (Sicoob Central)
}

DESPESAS PÚBLICAS COM SAÚDE E EDUCAÇÃO NOS MUNICÍPIOS DO ESPÍRITO SANTO: uma investigação empírica

Resumo: Este trabalho buscou verificar os determinantes dos gastos públicos com saúde e educação nos municípios do Espírito Santo, baseando-se na teoria do eleitor mediano. Os dados censitários referem-se ao ano de 2010. Constata que as principais variáveis que explicam as despesas públicas municipais com saúde e educação foram significantes e apresentaram os sinais esperados. Para saúde as principais variáveis foram: preço (tax-price), renda, população, IDH, percentual da população rural e densidade demográfica. Já para educação foram: preço, renda, população, IDH, percentual da população com até 15 anos e densidade demográfica. A elasticidade-preço revelou-se inelástica e a elasticidade-renda estimada permitiu referenciar os bens públicos relacionados à saúde e educação como de caráter normal/superior. Conclui que o coeficiente de congestionamento apresentou valor inferior à unidade, o que demonstra economias de escala a serem exploradas.

Palavras-chave: Teoria do eleitor mediano, Despesas públicas, Espírito Santo.

PUBLIC EXPENDITURE WITH HEALTH AND EDUCATION IN THE MUNICIPALITIES OF ESPÍRITO SANTO: an empirical investigation

Abstract: The objective of this paper was to verify the determinants of public expenditure on health and education in the municipalities of Espirito Santo, based on the median voter theory and the traditional econometric approach. Census data refer to 2010. For health the variables significant were: price (tax-price), income, population, IDH, percentage of rural population and population density. As for education were: price, income, population, IDH, percentage of population aged 15 years and population density. The price elasticity proved to be inelastic and the estimated income elasticity allowed to reference the public goods related to health and education as normal/superior. The coefficient of congestion effect showed a value less than unity both for health and for education, demonstrating the presence of economies of scale to be exploited for these public goods.

Key words: The median voter theory, Public expenditure, Espírito Santo. 
1 INTRODUÇÃO

0 artigo 18, da Constituição Federal Brasileira (CFB), de 1988, determina que a organização político-administrativa federativa compreende: a União, os estados, o Distrito Federal e os municípios, sendo que todos são autônomos. As principais competências para os municípios podem ser encontradas no artigo 30, que são, em síntese: a organização e prestação, direta ou sob regime de concessão ou permissão, dos serviços públicos de interesse local, incluindo 0 de transporte coletivo, que possui caráter essencial; manutenção, com a cooperação técnica e financeira da União e do estado, de programas de educação infantil e de ensino fundamental; e, prestação, também com cooperação técnica e financeira da União e do estado, de serviços de atendimento a saúde da população. Além disso, observa-se que existem muitas outras atribuições sob responsabilidade da União e/ou estados que são executadas e custeadas, em parte, pelos municípios (BREAMAEKER, 2003 apud BARCELOS, 2007).

Existem vários instrumentos com o objetivo de criar algum tipo de controle sobre os gastos públicos locais, mesmo quando diz respeito à responsabilidade exclusiva de municípios. Assim, tornam-se relevantes os dispositivos constitucionais e legais que restringem ou obrigam os governos locais a alocar uma parcela dos recursos arrecadados localmente ou recebidos por transferências de esferas maiores de governo em algumas funções consideradas prioritárias. Nesse caso, seja pelo objetivo de controlar os gastos ou pela relevância do serviço oferecido, tem-se garantido por lei que no mínimo $25 \%$ da receita dos municípios deve se destinar para educação, 15\% (também valor mínimo) para saúde e até $60 \%$ para pessoal (MENDES; SOUZA, 2006).

No que se refere aos gastos com saúde e educação, Giambiagi e Além (2000) afirmam que a intervenção do governo é justificada, tendo em vista que bons níveis de saúde e educação na sociedade resultam em externalidades positivas, no sentido de auxiliar na construção de oportunidades no presente e de um futuro cada vez mais promissor. Se esta é a visão da população ou não, o fato é: cada vez mais se cobra por melhorias nestas áreas, o que as tornam ponto forte nas campanhas eleitoreiras, seja com o objetivo de atrair votos ou, de fato, atender as necessidades dos cidadãos.

Segundo Mendes e Souza (2006), setores de saúde e educação já compõem a maior parcela dos gastos públicos municipais, remetendo quase a metade das suas despesas totais. Nos municípios do Espírito Santo não é diferente. No ano de 2002, os 78 municípios do estado gastaram no total cerca de $\mathrm{R} \$ 317,6$ milhões com saúde e, R\$ 514 milhões com educação, que somados representaram aproximadamente $42 \%$ das despesas 
orçamentárias nominais das prefeituras. Já no ano de 2012, os gastos com saúde e educação foram de aproximadamente $\mathrm{R} \$ 1,5$ bilhão e $\mathrm{R} \$$ 2,35 bilhões, respectivamente, equivalente a quase $46 \%$ das despesas nominais dos municípios. Em termos de montante, quando comparado o ano de 2002 e 2012, houve um aumento expressivo em torno de $\mathrm{R} \$ 3$ bilhões nos gastos com tais segmentos. Observa-se, portanto, 0 acréscimo dos gastos e 0 comprometimento de grande parte da receita municipal com esses setores (BRASIL, 2013).

Dentre as correntes que estudam a questão dos gastos públicos ${ }^{1}$, uma delas é a teoria da escolha pública² (public choice), que começou a ser desenvolvida em meados da década de 1950, ganhando ênfase com estudos realizados por Samuelson (1954). Posteriormente, avanços teóricos puderam ser vistos por Tibeout (1956), que considerou que os serviços fornecidos por governos locais são diferentes quando cidadãos têm livre mobilidade. Isto é, se um indivíduo, que transita de uma comunidade para outra, depara-se com diferentes níveis e tipos de serviços públicos prestados, esse escolherá o local que melhor satisfaça suas necessidades particulares. Tal fator resultaria em comunidades homogêneas e com serviços públicos similares (devido à competição entre as jurisdições) e, em uma situação de equilíbrio e com mercado eficiente, não seria possível um cidadão melhorar sua situação e recorrer a diferentes alternativas.
Até o início da década de 1970 era difícil justificar as escolhas das variáveis que determinavam os gastos públicos, pois as pesquisas empíricas eram baseadas em abordagens ad hoc. (BERGSTROM; GOODMAN, 1973). A partir deste período, uma série de estudos objetivou verificar os determinantes das despesas públicas fundamentando-se nos pressupostos microeconômicos da teoria do consumidor, tendo, como semelhança, a utilização da teoria do eleitor mediano, desenvolvida inicialmente por Bowen (1943), Black (1948), Downs (1957), entre outros. $\mathrm{Na}$ teoria do eleitor mediano a demanda comunitária é determinada pelo conjunto das demandas individuais de cada cidadão. Dessa forma, esta teoria considera que "[...] os candidatos formulam políticas com 0 intuito de ganhar eleições, ao invés de ganhar as eleições para formular políticas." (DOWNS, 1957, p. 28).

Mesmo com algumas críticas ${ }^{3}$, várias pesquisas têm corroborado a importância da teoria do eleitor mediano. A nível internacional, pode-se citar estudos de Borcherding e Deacon (1972), Bergstrom e Goodman (1973), Pommerehne (1978), Edwards (1992), Turnbull e Djoundourian (1994), Aronsson, Lundberg e Wikström (2000) e Sanz e Velazquez (2002). No Brasil, dentre os estudos sobre despesas públicas na esfera municipal, tem-se: Mendes (2005), Mendes e Souza (2006) e Barcelos (2007). Especificamente, para o estado do Espírito 
Santo, Monte (2011) analisou as despesas públicas a nível global (despesas totais), utilizando dados do ano de 2000.

Stiglitz (2000) ratifica a necessidade de estudos sobre gastos públicos, uma vez que os mesmos afetam variadas atividades e, seja no passado, no presente ou no futuro, influenciam diretamente a vida dos indivíduos. O cidadão é, ao mesmo tempo, contribuinte e beneficiário do gasto público, pagando certos impostos e recebendo algum tipo de benefício.

Ainda, segundo Rezende (2001), a busca por um bem público trata de duas reações de sentidos opostos. Uma refere-se à satisfação do consumo, que está subordinada a utilidade atribuída pelo individuo a um bem. $\mathrm{A}$ outra, diz respeito ao pagamento de impostos (visto como sacrifício ou desutilidade) para reproduzir os bens públicos, que acaba por reduzir a renda disponível para o consumo de bens privados.

De acordo com Giambiagi e Além (2000), existem funções que são típicas do governo. Destacam-se: a) saúde; b) educação; c) defesa nacional; d) policiamento; e) regulação; f) justiça; e, g) assistência social (alguns desses serviços são oferecidos também pelo setor privado, como é o caso de médicos, hospitais e escolas particulares). Tais funções impactam diretamente nas despesas do setor público e muitas vezes estes gastos não são realizados de maneira eficiente.
Dessa forma, levando em consideração 0 aumento das despesas públicas com saúde e educação; a constante cobrança por maior eficiência nos gastos públicos; e entendendo que estudos sobre a determinação das despesas públicas podem auxiliar no planejamento e dar suporte aos governos municipais quanto ao cumprimento de suas obrigações legais, torna-se importante verificar os determinantes dos gastos públicos com saúde e educação nos municípios do Espírito Santo.

\section{MODELO ECONÔMICO}

Existem diversas teorias que objetivam explicar, ainda que parcialmente, 0 comportamento dos gastos públicos, a saber: Lei de Wagner, o Modelo de Peacock e Wiseman e a Teoria da llusão Fiscal (CARDOSO; NASCIMENTO; PAIXÃO, 2012). Da mesma forma, como já descrito, diversos estudos buscaram avaliar as despesas públicas embasando-se na teoria do eleitor mediano.

Neste modelo, os indivíduos maximizam uma função de utilidade, escolhendo entre dois bens, $x$ (privado) e $z$ (público), e sujeitos a uma restrição orçamentária. Assume-se que o preço do bem privado é igual a 1 (um), e que todas as pessoas dentro de uma mesma localidade consomem a mesma quantidade do bem público (preço $p_{z}$ ). 
Assim, o leitor mediano exerce seu poder de voto buscando maximizar a função de utilidade expressa na Equação 1:

$$
U=U\left(x_{i}, z\right),(1)
$$

sendo que esta maximização está sujeita a uma restrição orçamentária (Equação 2):

$$
y_{m}=x+t_{i} b_{m},(2)
$$

em que $y_{m}$ é a renda do eleitor mediano; $b_{m}$, base do imposto; e, $t_{i}$, parcela do imposto.

No caso das demandas individuais, estas também dependem da restrição orçamentária do governo, conforme Equação 3:

$$
c Z=G+t B,(3)
$$

em que $c$ é o custo médio ou marginal constante da produção do serviço público; $t B$, receitas totais dos impostos; e, $G$, transferências intergovernamentais recebidas pela comunidade. Resolvendo a Equação 3 para $t$, chega-se à Equação 4:

$$
t=\frac{[c Z-G]}{B}
$$

\section{Bocherding e Deacon (1972)}

demonstraram que, devido ao congestionamento (rivalidade), o consumo do bem público depende não somente do seu volume total $(Z)$, mas também do tamanho da população de determinada comunidade $(N)$. Dessa maneira, baseando-se nos autores, descreve-se a função congestionamento, conforme Equação 5:

$$
Z=N^{\gamma} z,(5)
$$

em que $\gamma \quad$ representa 0 efeito congestionamento ou rivalidade. Este parâmetro também pode ser considerado uma medida de publicização do bem, já que reflete sua maior característica; a não-rivalidade.

Caso $\gamma$ seja igual à unidade, 0 bem é tipicamente privado, não havendo benefícios de economias de escala para sociedade e, sendo o consumo individual, igual a $1 / N$. Quando $\gamma$ for igual a zero, o bem é público puro (o bem é indivisível e não rival). Se $\gamma$ for maior que um, o bem é considerado supercongestionado marginalmente. Por fim, em situações em que $\gamma$ está entre zero e um, o bem é considerado semipúblico (ou semiprivado), com certos padrões de congestionamento, mas com economias de escala a serem exploradas.

Tomando-se as Equações 4 e 5, e substituindo-as na Equação 2 (restrição orçamentária do eleitor mediano), encontra-se a Equação 6:

$$
y_{a}=y_{m}+g\left(\frac{b_{m}}{b}\right)=x+\left(\frac{b_{m}}{b}\right) c N^{\gamma-1} z,(6)
$$


onde $y_{a}$ é a receita média aumentada por uma parcela das transferências intergovernamentais per capita; $g=G / N$; e, $b=B / N$, em que $B$ é a base do imposto total local. A renda total do eleitor mediano deve cobrir suas despesas privadas e sua parcela de custo na aquisição do serviço público $\left(b_{m} / b\right) c N^{\gamma-1} z$. A Equação 6 pode ser reescrita, dando origem à Equação 7:

$$
x=y_{m}+\left(\frac{b_{m}}{b}\right)\left[g-c N^{\gamma-1} z\right],(7)
$$

Ao substituir a Equação 7 na Equação 1, chega-se à Equação 8 :

$$
\max U=U\left[y_{m}+\left(\frac{b_{m}}{b}\right)\left[g-c N^{\gamma-1} z\right], z\right]
$$

Agora, supondo-se que a maximização da Equação 8 leva a função de demanda do eleitor mediano, para um serviço público local $(z)$, obtem-se a Equação 9 :

$$
z=z\left[y_{a}, \frac{b_{m}}{b}, N\right]
$$

Considerando-se 0 preço do serviço público (tax-price) como o custo individual de se adquirir uma unidade adicional de serviço público local, ele pode ser derivado, diferenciando-se $y_{a}$ com relação à $z$. Tem- se, então, o preço do imposto dado pela Equação 10:

$$
\frac{\delta y_{a}}{\delta z}=p=\left(\frac{b_{m}}{b}\right) c N^{\gamma-1},(10)
$$

O consumidor sabe seu próprio custo ou preço do imposto e é capaz de determinar a quantidade de serviço ${ }^{4}$ para a comunidade. Ao supor que a função de demanda da Equação $9\left[z=f\left(p_{i}, y_{a}\right]\right.$ possui elasticidades de renda e de preço constantes, determina-se a Equação 11:

$$
z=\alpha p^{\beta_{1}} y_{a}^{\beta_{2}}
$$

Substituindo a Equação 10 na Equação 11, a demanda de $z$ fica expressa pela Equação 12:

$$
z=\alpha\left[\left(\frac{b_{m}}{b}\right) c N^{\gamma-1}\right]^{\beta_{1}} y_{a}^{\beta_{2}}
$$

Inserindo-se a Equação 12 na Equação 5, encontra-se a Equação 13:

$$
Z=z N^{\gamma}=\alpha\left[\left(\frac{b_{m}}{b}\right) c N^{\gamma-1}\right]^{\beta_{1}} y_{a}^{\beta_{2}} N^{\gamma}
$$

Por fim, incluindo um vetor $\Omega$ de características socioeconômicas, que se acredita, afetam a demanda por bens públicos, e multiplicando a Equação 13 por $p$, tem-se 
uma função estimável da despesa pública municipal $(E)$, dada pela Equação 14:

$E=p Z=p z N^{\gamma}=\alpha\left[\left(\frac{b_{m}}{b}\right) c N^{\gamma-1}\right]^{\beta_{1}} y_{a}^{\beta_{2}} N^{\gamma} \Omega^{\beta_{i}}$,

Aplicando a propriedade logarítmica, a Equação para analisar as despesas públicas municipais fica expressa por:

$\ln E=k+\beta_{1}\left[\ln \left(\frac{b_{m}}{b}\right)\right]+\beta_{2} \ln \left(y_{a}\right)+$

$\beta_{3} \ln (N)+\sum_{i=4}^{n} \beta_{i}\left(\ln \Omega_{i}\right)+\varepsilon_{i}$

em que $k=\ln \alpha+\beta_{1} \ln c ; \beta_{1}$, elasticidadepreço da demanda; e, $\beta_{3}$ (elasticidadepopulação), satisfaz a Equação 16:

$$
\beta_{3}=\gamma\left(1+\beta_{1}\right)-\beta_{1}
$$

\section{MODELO ANALÍTICO}

Nesta pesquisa, com o intuito de explicar as despesas públicas com saúde e educação nos municípios capixabas, foi utilizada a análise de regressão linear múltipla, fazendo-se o uso do método de Mínimos Quadrados Ordinários (MQO).

O método de MQO pode ser representado, de forma simplificada, pela Equação 17 (GUJARATI; PORTER, 2008):

$$
\begin{array}{r}
Y_{i}=\hat{\beta}_{1}+\hat{\beta}_{2} X_{2 i}+\hat{\beta}_{3} X_{3 i}+\ldots+\hat{\beta}_{k} X_{k i}+\hat{u}_{i}, \\
i=1,2,3, \ldots, n,(17)
\end{array}
$$

em que $Y_{i}$ é a variável dependente; $X_{i}$, variáveis explicativas; $\hat{\beta}_{1}$, intercepto; $\hat{\beta}_{1} . .+\hat{\beta}_{k}$, coeficientes parciais de inclinação; $\hat{u}_{i}$, termo dos resíduos; e, $i$, i-ésima observação, sendo $n$ o tamanho da amostra.

A Equação 17 pode ser representada da seguinte forma:

$$
y=X \hat{\beta}+\hat{u},(18)
$$

ou, ainda, na forma matricial dada pela Equação 19:

$$
\begin{array}{r}
{\left[\begin{array}{c}
Y_{1} \\
Y_{2} \\
\vdots \\
Y_{n}
\end{array}\right]=\left[\begin{array}{ccccc}
1 & X_{21} & X_{31} & \cdots & X_{k 1} \\
1 & X_{22} & X_{32} & \cdots & X_{k 2} \\
\vdots & \vdots & \vdots & \vdots & \vdots \\
1 & X_{2 n} & X_{3 n} & \cdots & X_{k n}
\end{array}\right]\left[\begin{array}{c}
\hat{\beta}_{1} \\
\hat{\beta}_{2} \\
\vdots \\
\hat{\beta}_{k}
\end{array}\right]+\left[\begin{array}{c}
\hat{u}_{1} \\
\hat{u}_{2} \\
\vdots \\
\hat{u}_{k}
\end{array}\right],(19)} \\
y=X \hat{\beta}+\hat{u} \\
n \times 1 \\
n \times k
\end{array}
$$

em que $y$ representa o vetor coluna $n \times 1$ de observações sobre a variável dependente $Y$; $X$, matriz $n \times k$, dando $n$ observações sobre $k-1$ variáveis $X_{2}$ a $X_{k}$, sendo que a primeira coluna com os números $1 s$ (uns) representa 0 termo de intercepto. Esta matriz também é conhecida como matriz de dados; $\hat{\beta}$ é o vetor coluna de $k$ elementos com os estimadores de MQO dos coeficientes de regressão e; $\hat{u}$, o vetor coluna $n \times 1 \operatorname{com} n$ resíduos. 


\section{RESULTADOS E DISCUSSÕES}

\subsection{Apresentação das variáveis}

Os dados deste estudo foram do tipo corte transversal, sendo, em sua maioria, de ordem censitária. 0 ano de análise foi 0 exercício de 2010. A maior parte dos dados foi obtida do Instituto Brasileiro de Geografia e Estatística (IBGE), com exceção das receitas e das despesas com saúde e educação e das transferências intergovernamentais, provenientes da Secretaria do Tesouro Nacional (STN), e da intensidade da pobreza, obtida do Programa das Nações Unidas para o
Desenvolvimento (PNUD). As variáveis estão descritas no Quadro $1^{5}$.

\subsection{Análise descritiva das variáveis}

Esta subseção objetivou analisar as estatísticas descritivas (Tabela 1) das variáveis do estudo. Quanto à despesa com saúde, a média de gastos foi cerca de $\mathrm{R} \$ 15$ milhões. 0 valor máximo foi observado para Vitória, R\$ 173 milhões. Já o menor gasto com saúde ocorreu no município de Brejetuba, $\mathrm{R} \$$ 1,9 milhão. No que se refere à despesa média com educação, esta foi de aproximadamente $\mathrm{R} \$ 24$ milhões. A cidade que teve maior gasto

\section{Quadro 1 - Descrição das variáveis}

\begin{tabular}{|c|c|c|}
\hline Variáveis dependentes & Siglas & Descrição \\
\hline Despesa com saúde & (DESPSAUDE) & Despesa com saúde em $\mathrm{R} \$$. \\
\hline Despesa com educação & (DESPEDUC) & Despesa com educação em $\mathrm{R} \$$. \\
\hline Variáveis explicativas & Siglas & Descrição \\
\hline Parcela do imposto ou tax-price & (TXPRICE) & $\begin{array}{l}\text { Razão entre a receita tributária per-capita local e o } \\
\text { total de receita orçamentária de cada município. } \\
\text { Uma medida de esforço fiscal. }\end{array}$ \\
\hline Renda média ampliada & (RENDA) & $\begin{array}{l}\text { Soma entre a renda média de cada município e } \\
\text { produto da multiplicação do tax-price pelo montante } \\
\text { das transferências intergovernamentais recebidas } \\
\text { por cada município. }\end{array}$ \\
\hline População do município & (POP) & Número de habitantes de cada município. \\
\hline $\begin{array}{l}\text { Índice municipal de } \\
\text { desenvolvimento humano }\end{array}$ & $(\mathrm{IDH})$ & $\begin{array}{l}\text { Índice de desenvolvimento humano de cada } \\
\text { município. }\end{array}$ \\
\hline $\begin{array}{l}\text { Percentual da população com até } \\
15 \text { anos }\end{array}$ & (POPATE15ANOS) & $\begin{array}{l}\text { Razão entre a população de até } 15 \text { anos e a } \\
\text { população total do município. }\end{array}$ \\
\hline $\begin{array}{l}\text { Percentual da população com } \\
\text { mais de } 65 \text { anos }\end{array}$ & (POPMAISDE65ANOS) & $\begin{array}{l}\text { Razão entre a população com mais de } 65 \text { anos e a } \\
\text { população total do município. } \\
\text { Informação censitária obtida pela razão entre a }\end{array}$ \\
\hline Percentual da população rural & (POPRURAL) & $\begin{array}{l}\text { população residente na área rural e a população } \\
\text { total. }\end{array}$ \\
\hline Percentual da população urbana & (POPURBANA) & $\begin{array}{l}\text { Informação censitária obtida pela razão entre a } \\
\text { população residente na área urbana e a população } \\
\text { total. }\end{array}$ \\
\hline Densidade demográfica & (DENSDEMOG) & $\begin{array}{l}\text { Razão entre a população residente total e a área do } \\
\text { município. }\end{array}$ \\
\hline $\begin{array}{l}\text { Percentual de transferências } \\
\text { intergovernamentais. }\end{array}$ & (PTRANSF) & $\begin{array}{l}\text { Relação entre a transferência intergovernamental e } \\
\text { a receita orçamentária total. }\end{array}$ \\
\hline
\end{tabular}

Fonte: Elaborado pelos autores. 
Tabela 1 - Estatísticas descritivas das variáveis

\begin{tabular}{lrrrrr}
\hline \multicolumn{1}{c}{ Variável } & \multicolumn{1}{c}{ Média } & \multicolumn{1}{c}{ Mediana } & \multicolumn{1}{c}{ Máximo } & \multicolumn{1}{c}{ Mínimo } & \multicolumn{1}{c}{ Desvio-padrão } \\
\hline DESPSAUDE & 15.217 .039 & 7.498 .744 & 173.000 .000 & 1.520 .183 & 26.739 .072 \\
DESPEDUC & 23.653 .183 & 10.094 .818 & 255.000 .000 & 1.961 .236 & 43.547 .901 \\
TXPRICE & 0,0000029 & 0,00000253 & 0,00000952 & 0,00000048 & 0,00000172 \\
RENDA & 698,11 & 629,16 & $2.494,43$ & 415,44 & 304,43 \\
POP & $45.063,49$ & 17.986 & 414.586 & 4.561 & $83.759,20$ \\
IDH & 0,692 & 0,683 & 0,845 & 0,622 & 0,038 \\
POPATE15ANOS & 23,18 & 23,27 & 29,70 & 18,66 & 2,26 \\
POPMAISDE65ANOS & 8,10 & 8,04 & 11,77 & 4,51 & 1,62 \\
POPRURAL & 36,71 & 36,86 & 78,64 & 0,49 & 20,68 \\
POPURBANA & 63,30 & 63,14 & 100,00 & 21,36 & 20,70 \\
DENSDEMOG & 143,56 & 40,00 & $3.327,93$ & 10,17 & 452,47 \\
PTRANSF & 84,87 & 86,07 & 99,90 & 51,44 & 10,71 \\
\hline
\end{tabular}

Fonte: Elaborada pelos autores, a partir dos dados da pesquisa.

com educação foi Vitória, R\$ 255 milhões e, a de menor gasto, Divino de São Lourenço, com $\mathrm{R} \$ 1,9$ milhão.

A variável renda média ampliada teve valor médio de $\mathrm{R} \$ 698,11$, sendo que 0 município de Vitória apresentou a maior renda, $\mathrm{R} \$$ 2.494,43. Em contrapartida, Ibitirama demonstrou renda média de somente $\mathrm{R} \$$ 415,44. No que se refere ao Índice de Desenvolvimento Humano (IDH), a média encontrada foi de 0,692. Vitória encontra-se na primeira colocação do Espírito Santo com indicador de 0,845 e, Ibitirama, em último, 0,622. Vale destacar que, em média, $85 \%$ das receitas orçamentárias dos municípios do Espírito Santo foram provenientes de transferências intergovernamentais, 0 que reflete certa dependência dos municípios capixabas a estas transferências.

Por fim, é importante mencionar que todas as variáveis analisadas apresentaram elevado desvio-padrão em relação à média. Isto é reflexo das disparidades existentes entre os municípios do Estado, especialmente, os da região metropolitana e os do interior, sejam elas políticas, populacionais, geográficas, sociais, etc.

\subsection{Estimativas considerando as despesas com saúde 6}

Primeiramente, destaca-se que, para as estimativas econométricas, todas as variáveis foram transformadas por logaritmos. $\mathrm{Na}$ Tabela 2 são apresentados os resultados referentes às estimativas de MQO para as despesas públicas municipais capixabas com saúde. Foram realizados todos os testes estatísticos com o objetivo de verificar a boa especificação do modelo e possíveis problemas com as hipóteses do Modelo de Regressão Linear Clássico (MRLC). Verificou-se com 0 teste RESET que não há má especificação do modelo. O teste de autocorrelação (BreuschGodfrey) demonstrou que o modelo possui resíduos não autocorrelacionados. 0 teste de White não rejeitou a hipótese de ausência de heterocedasticidade ao nível de significância de 
Tabela 2 - Determinantes da despesa pública local com saúde ${ }^{7}$

\begin{tabular}{lrrrr}
\hline \multicolumn{1}{c}{ Variáveis } & Coeficientes & Erro-padrão & Estatística t & p-valor \\
\hline C & $-1,873^{\text {ns }}$ & 3,5943 & $-0,5210$ & 0,6040 \\
L(TAXPRICE) & $-0,3457^{* *}$ & 0,0983 & $-3,5143$ & 0,0008 \\
L(RENDA) & $1,5263^{* * *}$ & 0,2381 & 6,4097 & 0,0000 \\
L(POP) & $0,5039^{* * *}$ & 0,0881 & 5,7189 & 0,0000 \\
L(IDH) & $-2,7840^{*}$ & 1,4099 & $-1,9745$ & 0,0524 \\
L(POPATE15ANOS) & $0,0056^{\text {ns }}$ & 0,6061 & 0,0092 & 0,9926 \\
L(POPMAISDE65ANOS) & $0,0316^{\text {ns }}$ & 0,2474 & 0,1277 & 0,8987 \\
L(POPRURAL) & $-0,1337^{*}$ & 0,0723 & $-1,8481$ & 0,0690 \\
L(POPURBANA) & $0,0338^{\text {ns }}$ & 0,1443 & 0,2346 & 0,8152 \\
L(DENSDEMOG) & $-0,2167^{* * *}$ & 0,0573 & $-3,7785$ & 0,0003 \\
L(PTRANSF) & $-0,3481^{\mathrm{ns}}$ & 0,2724 & $-1,2782$ & 0,2056 \\
PAR. CONGESTIONAMENTO & & 0,2417 & & \\
\hline
\end{tabular}

$R^{2}=0,9397 \quad \bar{R}^{2}=0,9308 \quad$ Estatística $F=30,90590[0,0000]$

Fonte: Elaborada pelos autores, a partir dos dados da pesquisa.

Nota: 1) *** Significativo a 1\%, ** Significativo a 5\%, * Significativo a 10\%, ns Não-significativo a 10\%; 2) $L=$ Indica que as variáveis estão expressas em logaritmos.

$5 \%$. Já o teste de normalidade (Jarque-Bera) revelou que o modelo segue distribuição normal.

A estatística $\mathrm{F}$ demonstrou que a regressão global é estatisticamente significativa e o coeficiente de determinação ajustado $\left(\bar{R}^{2}=0,9308\right)$ revelou que $93,08 \%$ das variações das despesas públicas com saúde são explicadas pelas variações das variáveis explicativas presentes no modelo.

Verificou-se que as variáveis percentual da população até 15 anos, percentual da população com mais de 65 anos, percentual da população urbana e percentual de transferências intragovernamentais não foram significativas, do ponto de vista estatístico, na determinação das despesas públicas com saúde dos municípios do Espírito Santo. Além disso, a variável percentual de transferências intergovernamentais apresentou o sinal de seu coeficiente contrário ao esperado. Vale frisar que, conforme descrito anteriormente, as despesas com saúde têm valor mínimo fixado por lei, o que de certa forma tende a fazer com que os municípios mantenham seus gastos perto deste valor.

A elasticidade-preço negativa demonstrou que, à medida que se eleva a carga tributária municipal, reduz-se a demanda por serviços públicos locais. Neste caso, uma elevação de 1\% no preço do bem público (taxprice) resulta em uma redução de cerca de 0,35\% na demanda por bens públicos. 0 resultado indica uma demanda inelástica (bens básicos ou essenciais). Dessa forma, 0 governo teria uma boa margem para possíveis aumentos de impostos, uma vez que, elevado o preço do bem público, pouco impacta na demanda pelos mesmos. No que se refere à elasticidade-renda, esta foi positiva e superior à unidade, demonstrando que os bens públicos são de caráter normal/superior. 0 aumento de $1 \%$ na renda provoca um crescimento de $1,53 \%$ na demanda por bens públicos locais. 
De acordo com o observado, elasticidade-preço da demanda e elasticidaderenda, e baseando-se na teoria microeconômica, é notório que, em média, os bens públicos locais podem ser considerados de primeira necessidade para a população dos municípios do Espírito Santo, o que demonstra a importância de políticas públicas bem articuladas e eficientes para esta região.

$$
\text { Conforme } 0 \text { esperado, } 0
$$

coeficiente de variação da população total indicou que quanto maior a população, maior o gasto público. Assim, o aumento da população por si só é capaz de aumentar as despesas públicas, uma vez que se aumenta a demanda por saúde. Ressalta-se, aqui, o elevado coeficiente negativo encontrado para a variável IDH. Quando se eleva o IDH em 1\%, reduz-se o gasto público em 2,78\%. Vale ressaltar que 0 IDH engloba três indicadores fundamentais: renda, longevidade e educação, tornando uma variável essencial para a redução das despesas públicas. Assim, ao passo que os municípios capixabas se desenvolvem, tem-se uma grande queda na procura por bens públicos.

O coeficiente estimado para a população rural foi negativo, demonstrando que a demanda pública em comunidades rurais são reduzidas quando comparadas, por exemplo, aos centros urbanos. A população rural acaba por se deslocar de sua comunidade em busca de uma especialização e diversidade que, na grande maioria, só é encontrada nas grandes cidades. A variável densidade demográfica revelou-se significativa e com sinal negativo, fato que pode estar associado aos retornos de escala crescentes presentes em pequenos municípios. Em municípios onde a população é menor, tem-se um elevado custo médio dos serviços públicos, o que acaba por limitar a exploração de economias de escala na produção destes serviços, tornando a aplicação dos recursos ineficientes. De forma oposta, quanto maior a densidade demográfica, menor os custos dos serviços o que permite uma redução dos gastos públicos (MENDES, 2005).

O parâmetro de congestionamento foi estimado a partir da Equação 16. Este se refere ao grau de publicização dos bens públicos municipais. 0 valor encontrado $(0,2417)$ indica que, em média, existem substanciais economias de escala a serem exploradas pelos municípios capixabas, no que se refere às despesas com saúde. Isto é, há algum grau de não-rivalidade nos bens públicos da região, indicando que a agregação de novos consumidores resultaria em benefícios marginais superiores aos custos marginais de congestionamento. Assim sendo, os bens públicos (saúde) dos municípios do Espírito Santo podem ser classificados como semipúblicos ou semiprivados. Resultado semelhante foi encontrado por Mendes (2005) e Barcelos (2007) para os municípios brasileiros e MacMillan, Wilson e Arthur (1981) ao analisar pequenas comunidades urbanas do Canadá. Outros estudiosos como Borcherding 
e Deacon (1972), Bergstrom e Goodman (1973) encontraram estimativas próximas ou maiores que a unidade.

\subsection{Estimativas considerando as despesas com educação ${ }^{8}$}

Na Tabela 3 são apresentados os resultados referentes às estimativas de MQO para as despesas públicas municipais capixabas com educação. Testes estatísticos, com o objetivo de verificar a boa especificação do modelo e possíveis problemas com as hipóteses do MRLC, foram realizados. Com 0 teste RESET foi constatado que não há má especificação do modelo. 0 teste BreuschGodfrey demonstrou que o modelo possui resíduos não autocorrelacionados. 0 teste de White não rejeitou a hipótese de ausência de heterocedasticidade. $O$ teste de normalidade (Jarque-Bera) revelou que os resíduos seguem distribuição normal.
A regressão foi estatisticamente significativa, conforme demonstrado pela estatística $F$, e o coeficiente de determinação ajustado $\left(\bar{R}^{2}=0,9553\right)$ revelou que $95,53 \%$ das variações das despesas públicas com educação são explicadas pelas variações das variáveis explicativas presentes no modelo.

Nota-se que as variáveis percentual da população rural, percentual da população urbana e percentual de transferências intragovernamentais não foram significativas, do ponto de vista estatístico, na determinação das despesas públicas com educação dos municípios capixaba. Além disso, a variável percentual de transferências intergovernamentais apresentou o sinal de seu coeficiente negativo, sendo contrário ao esperado. Vale destacar que as despesas com educação também são fixadas por lei.

A elasticidade-preço apresentou sinal negativo, com efeitos relativamente pequenos, o que indica certa dificuldade na

Tabela 3 - Determinantes da despesa pública local com educação9

\begin{tabular}{lrrrr}
\hline \multicolumn{1}{c}{ Variáveis } & Coeficientes & Erro-padrão & Estatística t & p-valor \\
\hline C & $-4,6280^{*}$ & 2,4995 & $-1,8515$ & 0,0684 \\
L(TAXPRICE) & $-0,1593^{*}$ & 0,0863 & $-1,8444$ & 0,0695 \\
L(RENDA) & $1,2500^{* * *}$ & 0,2076 & 6,0205 & 0,0000 \\
L(POP) & $0,7597^{* * *}$ & 0,0773 & 9,8220 & 0,0000 \\
L(IDH) & $-2,6658^{* *}$ & 1,2268 & $-2,1729$ & 0,0333 \\
L(POPATE15ANOS) & $0,9891^{* * *}$ & 0,3419 & 2,8927 & 0,0051 \\
L(POPRURAL) & $-0,0826^{\text {ns }}$ & 0,0637 & $-1,2973$ & 0,1989 \\
L(POPURBANA) & $-0,0303^{\text {ns }}$ & 0,1192 & $-0,2542$ & 0,8000 \\
L(DENSDEMOG) & $-0,1317^{* * *}$ & 0,0492 & $-2,6741$ & 0,0094 \\
L(PTRANSF) & $-0,0057^{\text {ns }}$ & 0,2391 & $-0,0239$ & 0,9810 \\
PAR. CONGESTIONAMENTO & & 0,7141 & & \\
\hline \multicolumn{2}{c}{$R^{2}=0,9605$} & $\bar{R}^{2}=0,9553 \quad$ Estatística F $=58,71431[0,0000]$ & & \\
\hline
\end{tabular}

Fonte: Elaborada pelos autores, a partir dos dados da pesquisa.

Nota: 1) ${ }^{* * *}$ Significativo a $1 \%,{ }^{* *}$ Significativo a $5 \%,{ }^{*}$ Significativo a $10 \%$, ns Não-significativo a $10 \%$;

2) $L=$ Indica que as variáveis estão expressas em logaritmos. 
substituição dos bens públicos deste setor para o setor privado. Este fato, de certa forma, é resultado dos altos custos com a educação privada no Brasil. A elasticidade-renda é positiva e superior à unidade, demonstrando que os bens públicos são de caráter normal/superior. 0 aumento de $1 \%$ na renda provoca um crescimento de $1,25 \%$ na demanda por bens públicos locais. Fato que reforça a dificuldade na substituição deste bem público por um bem privado.

O coeficiente de variação da população total apresentou o sinal esperado e aponta que o tamanho da população influencia diretamente nos gastos públicos. Para o IDH foi encontrado um grande coeficiente negativo. Elevando o IDH em 1\%, tem-se a redução da despesa pública em 2,67\%.

Ao que diz respeito a variável percentual da população com até 15 anos, observou-se um parâmetro positivo, o que evidencia a relação direta existente entre a despesa desse setor e a população desta faixa etária. Quando, proporcionalmente, a participação de crianças e jovens é maior que a população total, 0 eleitor mediano representativo ambiciona por uma maior oferta de bens públicos de natureza educacional (BARCELOS, 2007). A variável densidade demográfica exibiu um sinal negativo, que igualmente dito na seção anterior, pode estar associado aos retornos de escala crescentes presentes em pequenos municípios.
0 parâmetro de congestionamento $(0,7141)$ reforça a conclusão de que a educação municipal capixaba permite ganhos de escala a serem explorados, resultado que se mostra compatível com a ideia de baixa rivalidade dessa função, uma vez que escolas e demais aparatos com educação permitem 0 compartilhamento a baixos custos marginais.

\section{CONCLUSÃO}

O objetivo deste trabalho foi estimar a demanda por bens públicos com saúde e educação dos municípios do estado do Espírito Santo, buscando verificar como a variação de fatores socioeconômicos, demográficos e geográficos impactam na demanda dos bens. 0 trabalho tomou como base o modelo do eleitor mediano, utilizandose da técnica econométrica de MQO.

Os principais resultados encontrados foram os seguintes:

1) No que diz respeito às despesas com saúde, as principais variáveis que explicaram as despesas públicas municipais foram: TAXPRICE, RENDA, POP, IDH, POPRURAL e DENSDEMOG. Destaca-se grande relevância das variáveis RENDA e IDH;

2) No caso das despesas com educação, as variáveis TAXPRICE, 
RENDA,

POP,

IDH, POPATE15ANOS e DENSDEMOG foram significativas e também apresentaram 0 sinal esperado. RENDA, IDH e DENSDEMOG se destacam pelo grande impacto nas determinações do gasto público com educação;

3) O parâmetro de congestionamento, tanto para saúde quanto educação, apresentou valor inferior à unidade, - que demonstra a presença de economias de escala a serem exploradas em ambas as funções. Isto é, ainda não há o esgotamento do consumo dos bens públicos nos municípios no Espírito Santo. Dessa forma, novos consumidores podem demandá-los, repartindo o custo do fornecimento, sem perda da utilidade. Assim, verifica-se que ainda existe espaço para a provisão destes bens públicos por parte das autoridades governamentais.

De forma geral, o estudo revelou que os bens públicos relacionados à saúde $\mathrm{e}$ educação podem ser considerados de primeira necessidade para as comunidades dos municípios do estado. Gastos mal planejados contribuem de forma negativa para o bem-estar dos cidadãos destes municípios. Políticas que, por exemplo, busquem elevar 0
IDH local, tendem a melhorar a situação geral da população e reduzir, de forma significativa, as despesas públicas locais. Em locais mais desenvolvidos, a população tende a depender menos dos gastos governamentais, uma vez que tem condições de migrar para 0 setor privado.

Conforme já mencionado, na introdução deste trabalho, existem funções que são eminentes do governo e impactam diretamente em seus gastos como: a) saúde; b) educação; c) defesa nacional; d) policiamento; e) regulação; f) justiça; e, g) assistência social (GIAMBIAGI; ALÉM, 2000). Tem-se a população exercendo dois papéis ao mesmo tempo: demandante e financiadora destes gastos públicos. Uma vez elevado 0 gasto dos indivíduos com bens públicos, temse uma redução no consumo de bens privados, pois se reduz a renda disponível.

Destaca-se que ao longo dos anos tem se notado um aumento significativo dos gastos públicos. Entretanto, na maioria das vezes, este aumento se dá em termos quantitativos e, não, qualitativos. Assim, quando este estudo quantifica os determinantes das despesas públicas com saúde e educação nos municípios do Espírito Santo, visa auxiliar nas ações governamentais locais, de forma que os seus gastos sejam realizados da forma mais eficiente possível, buscando qualidade e não apenas quantidade. 
Acredita-se que aumentar os gastos públicos, ainda que seja em suas funções essenciais, não seja suficiente para garantir serviços bons e que satisfaça os cidadãos. Faz-se preciso um planejamento governamental adequado para auxiliar na tomada de decisões quanto a financiamentos, realização e prioridades do destino das despesas públicas com saúde e educação. Logo, é necessária uma boa gestão, embora ainda fragilizada no setor público, com 0 intuito de direcionar com eficiência os gastos.

Por fim, cabe destacar que a teoria do eleitor mediano tem como pressuposto que os agentes sociais buscam maximizar seus interesses próprios e que esse estudo buscou, por meio da mesma, agregar elementos adicionais no que se refere às discussões em torno das despesas públicas com educação e saúde. Mesmo apresentando certas limitações, a teoria permite mensurar os efeitos que mudanças econômicas, sociais, demográficas e geográficas podem causar na demanda pelos bens públicos com educação e saúde. Entretanto, os modelos abordados nesta pesquisa não consideraram, e nem pretenderam considerar, por exemplo, o peso das estruturas sociais e das instituições, que podem interferir na tomada de decisões dos agentes públicos por meio de suas ações. Assim, trabalhos adicionais podem se desenvolvidos com o intuito de aprofundar e enriquecer os resultados aqui encontrados.

\section{REFERÊNCIAS}

ARONSSON, T.; LUNDBERG, J.; WIKSTRÖM, M. The impact of regional public expenditures on the local decision to spend. Regional Science and Urban Economics, [S. I.], v. 30, n. 2, p. 185-202, 2000.

BARCELOS, C. L. K. Determinantes da despesa pública local: um estudo empírico dos municípios brasileiros a luz do teorema do eleitor mediano. 2007. $111 \mathrm{f}$. Dissertação (Mestrado em Ciências Contábeis) - Programa Multi-institucional e Inter-regional de Pós-graduação em Ciências Contábeis, Universidade de Brasília, Universidade Federal da Paraíba, Universidade Federal de Pernambuco, Universidade Federal do Rio Grande do Norte, Brasília, DF, 2007.

BERGSTROM, T. C.; GOODMAN, R. P. Private demands for public goods. The American Economic Review, [S. I.], v. 63, n. 3, p. 280-296, jun. 1973.

BLACK, D. On the rationale of group decisionmaking. The Journal of Political Economy, Chicago, v. 56, n. 1, p. 23-34, feb. 1948.

BORCHERDING, T. E.; DEACON, R. T. The demand for the services of non-federal governments. The American Economic Review, [s. I.], v. 62, n. 5, p. 891-901, dec. 1972.

BOWEN, $\mathrm{H}$. The interpretation of voting in the allocation of economic resources, Quarterly Journal of Economics, Oxford, v. 58, n. 1, p. 27-48, nov. 1943.

BRASIL. Ministério da Fazenda. Secretaria do Tesouro Nacional. Contas Anuais. Brasília, DF, $2012 . \quad$ Disponível 
em:<https://www.tesouro.fazenda.gov.br/pt/co mponent/article/48-prefeituras-governosestaduais/767-contas-anuais>. Acesso em: 13 nov. 2013.

Presidência da República. Senado Federal. Constituição da República Federativa do Brasil de 1988. Brasília, DF, 2012.

CARDOSO, B. F.; NASCIMENTO, J. S.; PAIXÃO, A. N. Efeitos das transferências fiscais sobre as despesas dos estados brasileiros. Revista de Economia, Curitiba, v. 38, n. 2, p. 149-167, maio/ago. 2012.

DOWNS, A. An economic theory of democracy. New York: Harper, 1957.

EDWARDS, J. H. Y. Indivisibility and preference for collective provision. Regional Science and Urban Economics, [S. I.], v. 22, n. 4, p. 559-577, 1992.

GIAMBIAGI, F.; ALÉM, A. C. Finanças públicas: teoria e prática no Brasil. 2. ed. Rio de Janeiro: Elsiever, 2000.

GUJARATI, D. N.; PORTER, D. C. Basic econometrics. 5. ed. New York: McGrawHill//rwin, 2008.

MACMILLAN, M. L.; WILSON, R. W.; ARTHUR, L. M. The publicness of local public goods: evidence from Ontario municipalities. Canadian Journal of Economics, Columbia, v. 14, p. $596-608,1981$.

MENDES, C. C. A demanda por serviços públicos municipais no Brasil: a abordagem do eleitor mediano revisada. 2005. $196 \mathrm{f}$. Tese (Doutorado em Economia) - Departamento de Economia, Universidade de Brasília, Brasília, DF, 2005.

; SOUZA, M. C. S. Estimando a demanda por serviços públicos nos municípios brasileiros. Revista Brasileira de Economia, Rio de Janeiro, v. 60, n. 3, p. 281-296, jul./set. 2006.
MONTE, E. Z. Determinantes das despesas públicas municipais no Espírito Santo: a abordagem do eleitor mediano. In: ENCONTRO DE ECONOMIA CATARINENSE, CRESCIMENTO E SUSTENTABILIDADE, 5, 2011, Florianópolis. Anais... Florianópolis: APEC, 2011.

PEREIRA, P. T. A teoria da escolha pública (public choice): uma abordagem neoliberal? Análise Social, Lisboa, v. 32, n. 141, p. 419442, 1997.

POMMEREHNE, W. W. Institutional approaches to public expenditure: empirical evidence from Swiss municipalities. Journal of Public Economics, [S. I.], v. 9, n. 2, p. 255280, 1978.

REITER, M.; WEICHENRIEDER. Are public goods public?: a critical survey of the demand estimates for local public services. Finanzarchiv: Public Finace Analysis, [S. I.], v. 54, p. 374-408, 1997.

REZENDE, F. A. Finanças públicas. 2. ed. São Paulo: Atlas, 2001.

SAMUELSON, P. A. The pure theory of public expenditure. The Review of Economics and Statistics, Cambridge, MA, v. 36, n. 4, p. 387389, nov. 1954.

SANZ, I.; VELÁZQUEZ, F. J. Determinants of the composition of government expenditure by functions. Madrid: European Economy Group. Working paper 13, 2002.

STIGLITZ, J. E. Economics of the public sector. 3. ed. New York: W. W. Norton \& Company, 2000.

TIEBOUT, C. M. A pure theory of local expenditures. The Journal of Political Economy, Chicago, v. 64, n. 5, p. 416-424, oct. 1956.

TURNBULL, G. K.; DJOUNDOURIAN, S. S. The median voter hypothesis: evidence from 
general purpose local governments. Public Choice, v. 81, n. 3/4, p. 223-240, 1994.

NOTAS:

1 Nesta pesquisa, gastos e despesas públicas serão sinônimos.

2 Em Stiglitz (2000) é possível encontrar uma visão geral sobre a teoria da escolha pública. É importante dizer que, de acordo com Pereira (1997), a teoria da escolha pública foi a principal crítica teórica econômica que respalda a intervenção do Estado na economia - a economia do bem-estar. Neste ponto, não há concordância entre o tamanho e importância do Estado na economia. Enquanto a teoria do bemestar justifica a intervenção do governo pelos fracassos econômicos, a teoria da escolha pública veio clarificar os fracassos do governo e postular limites para a intervenção do governo na economia. Ainda, de acordo com Pereira (1997), a teoria da escolha pública trata-se de um programa de investigação, enquanto o pensamento neoliberal, de uma ideologia. As duas coisas, portanto, não devem ser confundidas.

${ }^{3}$ Mesmo sendo bastante difundida, a teoria do eleitor mediano tem recebido algumas críticas. Uma delas refere-se à agregação de preferências individuais para representar uma comunidade como um todo. Conforme apresentado por Mendes (2005), outros problemas são: erros de medida e presença de heterocedasticidade entre as variáveis, o que pode comprometer os resultados.

4 "Existem três razões que podem explicar o porquê dos eleitores perceberem, às vezes, de maneira errada os custos dos serviços públicos: ilusão fiscal, efeito flypaper e, complexidade da receita." (REITER; WEICHENRIEDER, 1997, p. 21).

${ }^{5}$ Variáveis como taxa de alfabetização, esperança de vida, distância da capital e etc. foram testadas e não apresentaram resultados satisfatórios, comprometendo o ajuste do modelo.

${ }^{6}$ Neste item, gastos com serviços públicos locais ou bens públicos referem-se exclusivamente a gastos municipais com saúde.

${ }^{7}$ Como forma de dar robustez aos resultados, estimouse um modelo somente com as variáveis significativas da Tabela 2. Os resultados não apresentaram alterações significativas e encontramse de posse dos autores.

${ }^{8}$ Neste item, gastos com serviços públicos locais ou bens públicos referem-se exclusivamente a gastos municipais com educação.
${ }_{9}$ Aqui, também, como forma de robustez, estimou-se um modelo somente com as variáveis significativas da Tabela 3. Os resultados não apresentaram alterações significativas.

\section{Edson Zambon Monte}

Economista

Doutor em Engenharia Ambiental

Professor do Departamento de Ciências Econômicas da Universidade Federal do Espírito Santo (UFES)

Email: edsonzambon@yahoo.com.br

\section{Thayane Pinheiro Largura}

Economista

Assistente financeira no Sistema de Cooperativas de Crédito do Brasil - Central (Sicoob Central)

E-mail: thayane.largura@hotmail.com

Universidade Federal do Espírito Santo - UFES

Av. Fernando Ferrari, 514, Goiabeiras, Vitória/ES CEP: 29075-910

Sistema de Cooperativas de Crédito do Brasil Central - Sicoob Central

Rua Constante Sodré, 305, Santa Lúcia, Vitória/ES

CEP: 29056-310 